\title{
Announcement: A Memory Researcher of the Hippocampus Has Gone, but Left His Mark
}

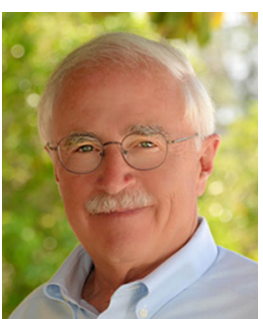

Howard B. Eichenbaum, a Distinguished Professor in the Department of Psychological and Brain Sciences at Boston University, and a leading figure in Neuroscience died in Boston on July 21, 2017. He was 69. He was also the director of BU's Center for Memory and Brain and the Laboratory of Cognitive Neurobiology. To many of us, Professor Eichenbaum was well-known as the 'memory researcher of the hippocampus', who has advanced our understanding of the fundamental nature and mechanisms of memory. Although his work focused in experiments in rodents, his work was an indispensable bridge between experimental work in animals and cognitive psychology. The several books and reviews he has written on this topic won widespread attention and will remain a precious chapter of neuroscience. He was also known as editor-in-chief of the scientific journal Hippocampus, which became a premier journal in this specialty field under his leadership. He supported eNeuro actively since launch being highly involved as a Reviewing Editor.

To some of us, Howard is known for his mentorship, guidance, and encouragement of scores of undergraduates, graduate students, and postdoctoral fellows and for his remarkable history of service and leadership. Most importantly, Howard was a generous friend, who will remain in our hearts (or more precisely in our hippocampusdependent episodic memory) forever.

György Buzsáki, Past Advisory Board

Christophe Bernard, Editor-in-Chief

Tim Bussey, Advisory Board

Brad Postle, Reviewing Editor

DOI:10.1523/ENEURO.0286-17.2017 